\title{
0 Conselho Tutelar e os desafios para a garantia dos direitos da criança e do adolescente
}

\author{
The Guardianship Council and the challenges to guarantee the rights of children and \\ adolescents
}

\author{
Carla Andreza Kelade Mezzina* \\ Eliana Bolorino Canteiro Martins**
}

\begin{abstract}
Resumo:
Este artigo pretende sintetizar resultados parciais obtidos com a pesquisa qualitativa referente à Dissertação de Mestrado intitulada: A garantia dos direitos da criança e do adolescente: eis o desafio $^{1}$, que propôs analisar a atuação do Conselho Tutelar para garantia dos direitos desse segmento populacional perante as alterações propostas pela Lei no $12.010 / 2009$ e compreender os desafios enfrentados por esse órgão de defesa na articulação com a rede de proteção social. Os resultados inferem que o ajuizamento dos fatos noticiados pelo Conselho Tutelar anterior à adoção de medidas na esfera administrativa, reforçava a judicialização e burocratização dos atendimentos, renovando velhos paradigmas conservadores de criminalização da pobreza. Portanto, considera-se benéfica a aplicabilidade deste novo fluxo de atendimento como mecanismo para determinação dos papéis de cada ator no Sistema de Garantias de Direitos, porém se evidencia a fragilidade da rede socioassistencial para a garantia da proteção integral da criança e do adolescente.
\end{abstract}

Palavras-chaves: Conselho tutelar. Criança e adolescente. Política pública. Proteção integral. Rede socioassistencial.

\begin{abstract}
:
This article intends to synthesize partial results obtained with the qualitative research related to the Master Dissertation entitled: The guarantee of the rights of the child and adolescents: The challenge, which proposed to analyze the actions taken by the Guardianship Council to guarantee the rights of this population segment before the changes proposed by the no. 12.010/2009 Law and understand the challenges faced by this defense body in articulation with the social protection network. The results show that the facts reported by the Guardianship Council prior to the adoption of measures at the administrative level reinforced the judicialization and bureaucratization of care, renewing old conservative paradigms of criminalization of poverty. Therefore, it is considered beneficial the applicability of this new flow of care as a mechanism to determine the roles of each actor in the Rights Guarantees System, however it was evident the fragility of the social assistance network to guarantee the integral protection of children and adolescents.
\end{abstract}

Keywords: Guardianship council. Child and teenager. Public policy. Integral protection. Social and social network.

\footnotetext{
* Assistente Social do Tribunal de Justiça do Estado de São Paulo; mestre em Serviço Social pela Universidade Estadual Paulista "Júlio M esquita Filho"- UNESP - Franca (SP); e-mail: carlakelade@ hotmail.com

** Assistente Social e docente do Depto. de Serviço Social da UNESP/Franca (SP), doutora em Serviço Social pela Pontifícia Universidade Católica de São Paulo - PUC/SP; Líder do Grupo de Estudos e Pesquisas sobre Serviço Social na Educação - GEPESSE, e-mail: elianacanteiro@terra.com.br

${ }^{1}$ Dissertação de Mestrado defendida em 2017, no Programa de Pós-Graduação em Serviço Social da Faculdade de Ciências Humanas e Sociais "Júlio de M esquita Filho" - UNESP/Campus de Franca (SP).
} 


\section{Introdução}

Este texto apresenta o resultado parcial da pesquisa de Dissertação intitulada "A garantia dos direitos da criança e do adolescente: eis o desafio", que adotou como percurso metodológico para construção do conhecimento a revisão bibliográfica para retomada de referenciais teóricos sobre as incidências históricas referentes à problemática da criança e do adolescente desde a fase colonial, perpassando pela implantação do Código de M enores e suas respectivas alterações, buscando compreender à proteção integral fundamentada pela Constituição Federal (BRASIL, 1988) e regulamentada pelo Estatuto da Criança e do Adolescente (ECA - 1990) e respectivas modificações.

Contemplou-se à retomada histórica da implantação do Estado Democrático de Direito brasileiro, elencando síntese desse processo para a conquista dos direitos de cidadania e os aspectos relacionados a importância da equipe técnica, auxiliares do juizado da infância e da juventude, destacando especificamente à incorporação do assistente social e à análise documental da Lei no 12.010 (BRASIL, 2009), no intuito de apreender e analisar as entrelinhas desta legislação.

0 universo desta pesquisa constituiu-se de um município de médio porte situado no interior do Estado de São Paulo - tendo como participantes da pesquisa cinco Conselheiros Tutelares (órgão elencado pelo ECA para proteger e garantir os direitos da criança e do adolescente) e cinco assistentes sociais (inseridos em equipamentos sociais da rede socioassistencial que executam a política pública de atenção à criança e ao adolescente no município onde foi realizada a pesquisa).

Realizou-se a pesquisa de campo de abordagem qualitativa, utilizando-se como técnica de coleta de dados a entrevista semiestruturada, devidamente gravadas para 0 registro minucioso dos relatos, tendo como perspectiva para a análise e interpretação dos resultados obtidos o materialismo histórico-dialético. $\mathrm{Na}$ apresentação dos resultados foram utilizados nomes fictícios para resguardar a identificação dos participantes. Os conselheiros tutelares foram denominados por espécies de flores: Jasmim, Lis, Margarida, Rosa e Violeta; e os profissionais assistentes sociais foram indicados por nome de escritores brasileiros: Machado de Assis, Cecília M eireles, Clarice Lispector e Raquel de Queiroz.

Assim, objetiva-se neste artigo traçar reflexões sobre o novo fluxo de atendimento proposto pelas alterações na Lei № 12.010 (BRASIL, 2009) e reiterado pelo Parecer CIJ $n$ o 04/2010 da Coordenadoria da Infância e Juventude do TJSP, interpretando as possibilidades 
e os limites enfrentados pelo Conselho Tutelar para garantia dos direitos da criança e do adolescente na interlocução com a rede socioassistencial.

As mudanças trazidas pela Lei ㄲo 12.010 (BRASIL, 2009), a qual alterou a Lei № 8.069/1990 - Estatuto da Criança e do Adolescente (ECA) - propôs reformas referentes à importância das políticas públicas para assegurar os direitos sociais às crianças e aos adolescentes. Para tanto, indicou-se a integração operacional de órgãos como o Judiciário, 0 Ministério Público, a Defensoria Pública, o Conselho Tutelar e os operadores das políticas setoriais, com vistas a atuar prioritariamente na proteção integral e na garantia dos direitos desse segmento populacional.

Com a promulgação do Estatuto da Criança e do Adolescente (ECA/1990), determinou-se aos Juizados da Infância e Juventude a responsabilidade dos aspectos jurisdicionais, ficando a cargo do Conselho Tutelar os aspectos administrativos.

O Parecer $\mathrm{ClJ}$ no 04/2010 definiu um reordenamento de ações e revisões de papéis (do Judiciário, Ministério Público, Conselho Tutelar e dos operadores das políticas setoriais), especificamente com a articulação e monitoramento do Conselho Tutelar, alterado a partir da vigência da Lei № 12.010 (BRASIL, 2009) que enfatizou a determinação do não ajuizamento de "procedimentos verificatórios", conhecidos como "processos de providência". (SÃO PAULO, 2010.)

Dessa forma, no cenário contemporâneo o Conselho Tutelar é responsável exclusivamente, desde a implantação do Estatuto da Criança e do Adolescente e corroborado pelo Parecer $\mathrm{ClJ}$ no 04/2010, por estabelecer o processo de apuração da realidade social apresentada e acionar a rede socioassistencial para atuar no contexto de risco ou de vulnerabilidade social que se encontram expostas crianças e adolescentes.

Sendo assim, alterou-se o fluxograma de atendimento das demandas sociais referentes aos segmentos criança e adolescente, ou seja, aciona-se o M inistério Público, o Poder Judiciário e, respectivamente, à equipe técnica da Vara da Infância e Juventude após esgotar as possibilidades de permanência da criança e do adolescente em sua família de origem.

O Estatuto da Criança e do Adolescente identifica direitos, deveres e responsabilidades, onde tais prerrogativas impulsionaram a prever um órgão de proteção e exigibilidade de direitos que se trata do Conselho Tutelar, que abrange em sua essência aspectos como democracia, desjudicialização e agilidade no atendimento. 
A compreensão mais específica e abrangente desta legislação permite questionar se esse órgão consegue erradicar práticas autoritárias, repressivas e criminalizadoras da pobreza; efetivar princípios que o define na lei como autônomo e não jurisdicional, e se seus membros compreendem o significado de suas atribuições e 0 impacto social que 0 desenvolvimento de suas funções implicará na garantia dos direitos da Criança e do adolescente.

Diante disso, considerando que já passaram vários anos desde a promulgação do referido parecer, houve tempo suficiente para sua aplicabilidade e possível avaliação da sua efetividade. É justamente neste sentido que a referida pesquisa problematizou essa nova organização de fluxo de atendimento aos menores de idade que possuem os direitos fundamentais ameaçados ou violados, contribuindo assim na construção de indicadores para analisar os resultados da aplicabilidade do Parecer $\mathrm{ClJ}$ no 4/2010 da Coordenadoria da Infância e Juventude, do Tribunal de Justiça do Estado de São Paulo, nestes anos de sua implantação.

\section{A efetivação dos direitos da criança e do adolescente: percepção do Conselho Tutelar e da rede socioassistencial}

Inicialmente trataremos neste item sobre o processo histórico de construção dos direitos da criança e do adolescente, conquistando mecanismos legislativos e científicos para a compreensão da representação social da infância e adolescência no país. Elegeu-se como recorte a década de 1980 em que a sociedade brasileira vivenciou o reencontro com a democracia, iniciado em meados dos anos de 1970, com os movimentos sociais que se caracterizaram por delatar formas de opressão e exclusão social, contribuindo para a introdução de direitos de cidadania que antes não constavam no nosso sistema jurídico, culminando na elaboração de uma nova constituição federal.

Este processo resultou na crise política vivenciada no início da década de 1980, ocasionando 0 avanço da abertura democrática e a desintegração do regime ditatorial mediante a introdução de preceitos na Constituição Federal (BRASIL, 1988) como a descentralização, o controle social e a participação da sociedade civil.

A Carta Magna preconizou visibilidade a infância e adolescência, estabelecendo princípios como a proteção integral e a prioridade absoluta. Neste sentido, o surgimento de legislações infraconstitucionais teve como objetivo validar os princípios contidos na 
Constituição Federal (BRASIL, 1988), motivo pelo qual citaremos breve percurso do ECA diante da evolução, significados, limites e desdobramentos da construção de uma política de atenção ao segmento infanto-juvenil.

O Estatuto da Criança e do Adolescente (Lei o 8.069, de 13 de julho de 1990) ratificou os princípios contidos na Constituição "Cidadã", delimitando a necessidade da criação de políticas públicas que atendam os direitos assegurados nesta legislação. Enfatizase que normativas internacionais inspiraram discussões na construção desta legislação, dentre elas: a Declaração Universal dos Direitos da Criança, promulgada pela Organização das Nações Unidas (ONU, 1959), e a Convenção Internacional sobre os Direitos da Criança, em 1989 (BRASIL, 1990).

Salienta-se que esta legislação previu a criação do Conselho Tutelar como um órgão inovador e com a função de coibir ameaças e violação de direitos, atribuindo-Ihe legitimidade ao definir características como permanência e autonomia que significa independência para representação do interesse prioritário na proteção de crianças e adolescentes e tomada das decisões em conjunto, conhecida como reunião de colegiado. (BRASIL, 1990). Além do Conselho Tutelar a lei previu a implantação de estruturas para efetivação deste fundamento nas esferas nacional, estadual e municipal: Conselhos dos Direitos da Criança e do Adolescente e os Fundos para Infância e Adolescência (FIA) (COSTA, 2002).

Ao longo desta trajetória ocorreram debates que culminaram em alterações de artigos do Estatuto da Criança e do Adolescente (Lei n. 12.010, de 3 de agosto de 2009 (BRASIL, 2009)), alvo de discussão da referida pesquisa, os quais produziram uma reforma significativa no Estatuto da Criança e do Adolescente, uma vez que estabeleceu um aperfeiçoamento da sistemática prevista para garantia dos direitos. Proporcionou a apreensão da Política da Infância e da Adolescência e da atuação dos órgãos que compõem - Sistema de Garantias de Direitos, com intuito de aperfeiçoar 0 atendimento desse segmento de forma coerente com o novo paradigma da proteção integral.

Nesta concepção o Conselho Tutelar assumiu papel de extrema importância como um mecanismo extrajudicial de atuação na defesa dos direitos do segmento infanto-juvenil.

A pesquisa revelou pela análise documental que 0 advento da Lei $n-12.010$ (BRASIL, 2009) promoveu avanços normativos, referenciando os mecanismos de defesa, proteção e promoção dos direitos dos menores de idade. Porém, é imperativa a necessidade de realizar 
estudos que confrontem o legal e o real para analisar como ocorre a operacionalização dessas mudanças na realidade social e na vida dessas crianças, adolescentes e suas respectivas famílias, que fazem parte desse contexto.

Os depoimentos dos conselheiros tutelares e dos assistentes sociais que atuam na política de atenção à infância e adolescência no município pesquisado, demonstraram que um percentual significativo de profissionais participantes deste estudo (56\%) desconhecia a existência deste parecer. Entretanto os relatos indicaram que indubitavelmente tratou-se de um processo aparentemente natural a estes participantes, conforme retratam os depoimentos:

Quando entramos no Conselho Tutelar houve uma reunião, eu não recordo o nome da Juíza, mas podemos buscar aqui, a qual nos informou que até então existia um procedimento de pedidos de providências. Que a partir da vigência da Lei, em 2009, começou a vigorar outra metodologia de trabalho e deixamos de pedir para que o Judiciário tomasse as providências e sim o Conselho Tutelar. Então quando esgotamos o procedimento, encaminhamos o fato a Promotoria que o remete ao Juizado. (Rosa - Conselheira Tutelar).

Observa-se, baseando-se nos depoimentos dos profissionais participantes deste estudo, que a divulgação deste documento (Parecer CIJ no 04/2010) restringiu-se a uma reunião realizada pelo Poder Judiciário desta Comarca, no ano de 2013, para veicular orientação aos conselheiros tutelares e à rede socioassistencial sobre as novas diretrizes procedimentais estabelecidas pela Lei ํo 12.010 (BRASIL, 2009).

Sendo assim, considera-se que a dimensão informativa e educativa ${ }^{2}$ dessa ação sobre o aperfeiçoamento da sistemática de atendimento proposta pela Lei $\mathrm{n} 012.010$ (BRASIL, 2009), deveria estender a cada nova gestão do Conselho Tutelar diante da rotatividade destes profissionais e da necessidade da capacitação continuada deste órgão de defesa, conforme estabelecido no próprio ECA.

\footnotetext{
${ }^{2}$ A recomendação aos Magistrados proposta pela Coordenadoria da Infância e Juventude do TJSP está expressa no Parecer ClJ no 04/2010: 1- Realizar, tanto quanto possível, reunião com os conselheiros tutelares, diretor regional/municipal de educação, responsável da secretaria de saúde pelo atendimento a crianças e adolescentes, delegados e comandantes da polícia militar e guarda civil, representante do Ministério Público e Defensoria esclarecendo que a apuração inicial de fatos relacionados a ameaça ou violação de direitos de crianças e adolescentes deve ser feito por serviço específico de atendimento da Prefeitura Municipal, com monitoramento pelo Conselho Tutelar; 2 - Orientar o Conselho Tutelar de que só deve representar ao juízo depois de ter os fatos apurados, anexando à representação as provas. Caso haja falta de atendimento a medidas aplicadas, o Conselho deve instruir a representação com o termo de aplicação da medida devidamente assinado pelo destinatário, o encaminhamento ao serviço e informação escrita do serviço de que não houve comparecimento, relatando estes fatos na representação. (SÃO PAULO, 2010, p. 2).
} 
De acordo com o conteúdo deste parecer, os pedidos de providência supostamente estavam associados à dimensão do poder institucional ao não possibilitar às famílias ou indivíduos o direito ao contraditório e à ampla defesa, conforme preconiza a Carta Magna em vigência no Brasil. Destaca-se também que essa mudança é substancial e não meramente teórica, conforme afirma, Milani e Volpato (2011, p. 12):

A mudança não é meramente teórica, resulta na qualidade de atuação da justiça. Não é um esvaziamento de funções a partir do Pedido de Providências, é qualidade de intervenção, em situação que exija a atuação judicial e aplicação da lei. Assim, estabelece-se uma nova metodologia de trabalho, um olhar crítico frente às políticas públicas e contato sistemático com a rede.

Além disso, pode-se afirmar que o Poder Judiciário usurpava uma função que deveria ser exercida pelo Conselho Tutelar e pelo Poder Público quanto ao acompanhamento das famílias, que na maioria das vezes não haviam sido submetidas ao encaminhamento para serviços especializados quando se identificava situação de ameaça ou violação de direitos da criança e do adolescente.

De acordo com Lopes $(2014$, p. 73) "[...] a rede efetivamente atuante faz com que crianças e adolescentes sejam reconhecidos como sujeitos de direitos e tenham políticas públicas sérias para atender às demandas levantadas por meio dos diagnósticos elaborados pelo CMDCA".

Não se pode deixar de mencionar que no conteúdo dos pedidos de providência está velada a existência das mais variadas formas de expressões da questão social. No entanto, o ajuizamento deste tipo de ação estabelece processo de judicialização da vida privada pela ausência de serviços e programas ofertados pela rede socioassistencial, o que inclusive deveria ser objeto de ajuizamento de ação civil pública proposta pelo M inistério Público ou pela Defensoria Pública, após representação do Conselho Tutelar. Aliás, o processo de judicialização das expressões da questão social está presente no contexto brasileiro, intensificado após a Constituição Federal (BRASIL, 1988), exigindo atuação incisiva do Poder Judiciário.

A judicialização das políticas públicas caracteriza-se pelo crescimento expressivo de processos judiciais para assegurar o acesso aos direitos sociais previstos na Constituição pátria, tendo em vista que a materialização da proteção social somente é possível pela ampliação da ação do Estado (SIERRA, 2011). Por outro lado, o aumento de ações judiciais 
traduz a inexistência ou insuficiência das políticas públicas e o descompromisso do Estado (avanço do neoliberalismo) em prover os direitos sociais e coletivos.

De maneira geral a judicialização demonstra aspecto positivo (o Judiciário assegura os anseios sociais não concedidos pelo Poder Legislativo) e aspecto negativo (o enfraquecimento deste Poder), o que revela que estes direitos não são concretizados de forma espontânea. “Este fenômeno caracteriza-se pela transferência, para o Poder Judiciário, da responsabilidade de promover o enfrentamento à questão social, na perspectiva de efetivação dos direitos humanos." (AGUINSKY; ALENCASTRO, 2006, p. 26).

Indagou-se aos participantes do estudo se as mudanças propostas por este parecer alteraram à operacionalidade do trabalho em sua instituição e em caso afirmativo, em quais aspectos houve substantiva transformação. Na análise dos dados parte significativa dos entrevistados (54\%) destacou que não houve mudanças.

A maioria dos conselheiros tutelares disse que, ao ingressar neste órgão, iniciaram a atuação pautada na sistemática de atendimento proposta pela Lei no 12.010 (BRASIL, 2009), articulando a rede socioassistencial para o cumprimento da legislação e da atribuição de cada ator do Sistema de Garantias de Direito da Criança e do Adolescente (SGDCA).

Já uma parcela expressiva dos assistentes sociais expôs que sempre foi de competência do Conselho Tutelar e da rede socioassistencial de acordo com as legislações, que esgotem os recursos existentes para posterior encaminhamento aos órgãos da justiça como o Ministério Público e Poder Judiciário.

Cabe ressaltar que o desconhecimento da legislação por parte dos conselheiros tutelares desencadeia o risco de atuar em funções que não lhes competem e acatar arbitrariedades principalmente por profissionais do sistema de justiça, o que impede sua concretização como mecanismo de exigibilidade de direitos, como órgão autônomo e não jurisdicional previsto pelo artigo 131, do Estatuto da Criança e do Adolescente.

Konzen (2000), ao se referir à autonomia do Conselho Tutelar, define que este órgão não está exposto a qualquer controle hierárquico ou político que possa interferir em suas decisões e também pontua sobre o caráter não jurisdicional ao situá-lo como responsável apenas pela adoção de medidas na esfera administrativa.

Andrade (2000) também traz uma discussão muito presente no cenário contemporâneo e pertinente nesse contexto: 
[...] grande tem sido o contingente de conselheiros que, no lugar de promover a criança, o adolescente e sua família, garantindo direitos e interesses, tem apenas perpetuado a ação do controle dos indivíduos antes exercida pela polícia, pelo poder judiciário e outras formas privadas de controle. (ANDRADE, 2000, p. 43).

A questão que está posta como desafio refere-se à prevalência da submissão dos muitos Conselhos Tutelares aos arbítrios da justiça e o despreparo em fortalecer que as decisões deste órgão sejam tomadas pelo colegiado, conforme proposto pelo Estatuto da Criança e do Adolescente, como mecanismo de exigibilidade de direitos. Lopes (2014, p. 31) afirma que "[...] não podemos falar em autonomia sem um bom Colegiado. É preciso que a sociedade e os conselheiros que atuam de forma equivocada entendam que a autonomia é do Colegiado e não do Conselheiro."

Torna-se importante retomar o artigo $26^{3}$ que enfatiza que a atuação deste órgão deve se voltar à desjudicialização, desburocratização e agilidade nos atendimentos. Ainda no artigo $29^{4}$ desta resolução, prevê-se a articulação de ações para agilizar o atendimento por órgãos governamentais e não governamentais encarregados pela execução das políticas de atenção aos menores e sua respectiva família.

Em vista disso, o ajuizamento dos fatos noticiados pelo Conselho Tutelar reforça a burocratização dos atendimentos e a violação de direitos de crianças e adolescentes, eximindo do cumprimento dos dispositivos elencados pelo Estatuto da Criança e do Adolescente e demais leis infraconstitucionais que abordam funções das políticas setoriais.

O depoimento de um dos assistentes sociais participantes do estudo retratou indubitavelmente que a própria rede reforça os mecanismos para camuflar suas debilidades e falhas, não efetuando suas atribuições designadas pela Política Nacional de Assistência Social (PNAS), pelo Sistema único de Assistência Social (SUAS) e pela Tipificação dos Serviços socioassistenciais, reproduzindo o ideário neoliberal de controle e culpabilização das famílias pelas expressões da questão social nas quais estão expostas.

Eu acredito que não. Eu acredito, na verdade, que este parecer veio para contestar o que já era de fato. 0 próprio SUAS já prevê que é de competência do Conselho Tutelar, é de competência da rede socioassistencial que todas as providências sejam tomadas antes de se levar ao Ministério Público [...] Porque eu vou levar para o Ministério Público uma coisa que eu sei que vai voltar para mim mesmo?

\footnotetext{
${ }^{3}$ Art. 26. A atuação do Conselho Tutelar deve ser voltada à solução efetiva e definitiva dos casos atendidos, com o objetivo de desjudicializar, desburocratizar e agilizar o atendimento das crianças e dos adolescentes, ressalvado as disposições previstas na Lei $n 08.069$, de 13 de julho de 1990.

${ }^{4}$ Art. 29. 0 Conselho Tutelar articulará ações para o estrito cumprimento de suas atribuições de modo a agilizar 0 atendimento junto aos órgãos governamentais e não governamentais encarregados da execução das políticas de atendimento de crianças, adolescentes e suas respectivas famílias.
} 
Que eu sei que é a rede que vai ter que trabalhar. Que é o Conselho Tutelar que vai ter que trabalhar. Então, na verdade, eu via o pedido de providência como uma retirada de culpa. Eu não estou sabendo muito que fazer; eu não estou tendo muito apoio; deixa levar ao M inistério Público, porque se acontecer alguma coisa eu estou livre dessa. Eu via mesmo como um escape dos profissionais, porque são coisas que você tem que resolver. Agora coisas que fogem de sua competência, aí com certeza têm que ser levada ao Ministério Público para ser resolvido em conjunto, porque foge da competência. (Cecília Meireles - Assistente Social).

Primeiramente, o desconhecimento da legislação por conselheiros tutelares desencadeia o risco de atuarem em funções que não thes competem e acatar arbitrariedades principalmente por profissionais do sistema de justiça, o que impede sua concretização como mecanismo de exigibilidade de direitos e como órgão autônomo não jurisdicional previsto pelo artigo 131, do Estatuto da Criança e do Adolescente.

A questão que está posta como desafio refere-se à prevalência da submissão dos muitos Conselhos Tutelares aos arbítrios da justiça e, principalmente, o despreparo em fortalecer que as decisões deste órgão sejam tomadas pelo colegiado - conforme proposto pelo Estatuto da Criança e do Adolescente, como mecanismo de exigibilidade de direitos.

É oportuno mencionar que um dos depoimentos dos profissionais assistentes sociais realçou a imprescindibilidade do investimento na estrutura física, assessoria jurídica e capacitação continuada diante do imensurável papel deste órgão aplicador das medidas de proteção previstas pelo Estatuto da Criança e do Adolescente.

Eu não vi alteração, pois quando cheguei já era dessa forma. Eu só vejo uma crítica construtiva, já que é para ser assim, ter um amparo melhor, uma garantia melhor para esse Conselho, tanto de logística quanto de apoio jurídico, que eu saiba não tem esse apoio jurídico lá no Conselho. Então como o CREAS tem o seu apoio jurídico que é essencial, também deveria ter por lá. M uitas vezes, um conselheiro toma uma decisão baseado em conjunto (conselheiro e conselheiro) e não tem um apoio jurídico. Eu vejo se é para ser dessa forma, realmente quando você descentraliza muitas coisas dão resultados, mas você tem que preparar melhor a equipe lá. (Machado de Assis - Assistente Social).

Segundo a Resolução № 170 do Conanda (2014), cada município implantará e manterá o Conselho Tutelar que deverá estar previsto em lei orçamentária municipal, responsável inclusive pelo custeio com remuneração, formação continuada e execução de suas atividades. Todavia, o que se constata é a instabilidade de investimento neste órgão decorrente da falta de efetividade de funcionamento do Conselho Municipal de Direitos da Criança e do Adolescente (CMDCA), órgão delegado a garantir à adoção de medidas administrativas e judiciais quando a lei local não assegura 0 que está previsto para 0 adequado funcionamento do Conselho Tutelar. 
Diante das pontuações acima desenvolvidas, considera-se que o desafio de concretizar direitos perpassa pelo desenvolvimento das políticas de atendimento à criança e ao adolescente, motivo pelo qual se abordará em seguida as possibilidades e limites do Conselho Tutelar na articulação com a rede socioassistencial.

\section{Possibilidades e limites do Conselho Tutelar na articulação com a rede socioassistencial}

Conforme descrito no item anterior, o Parecer CIJ no 04/2010 (SÃO PAULO, 2010) emitido pela Coordenadoria da Infância e Juventude do Tribunal de Justiça do Estado de São Paulo, definiu um reordenamento de ações e revisões de papéis em virtude da vigência da Lei no 12.010 (BRASIL, 2009), o qual estabeleceu a articulação e monitoramento do Conselho Tutelar, recomendando-se o não ajuizamento de processos conhecidos como "pedidos de providência". Em razão disso, a interlocução entre Conselho Tutelar e rede socioassistencial faz-se fundamental para efetivação das diretrizes estabelecidas pelo Estatuto da Criança e do Adolescente referente à importância das políticas públicas para assegurar os direitos sociais a crianças e adolescentes.

Os profissionais que atuam nos órgãos que integram o Sistema de Garantia de Direitos da Criança e do Adolescente possuem o dever ético de compreender e interpretar criticamente a realidade na qual atuam, identificando-a como um processo dinâmico que não prevê aspectos lineares ou estáticos.

Não há como analisar a realidade concreta sem compreender a categoria mediação, uma das variantes centrais da dialética dividida nas dimensões ontológica - conhecimento do real, e reflexiva - transpõe o plano da imediaticidade (aparência) para a apreensão da essência reedificada pelo próprio movimento do objeto, na perspectiva da totalidade. Assim, a categoria mediação facilita conhecer a realidade e romper com a aparência dos fatos empíricos, ocasionando conexões que se instauram a partir da síntese das múltiplas determinações. (M ARTINELLI; M ORAES, 2012).

Como diz Andrade (2000), o ECA define qual é o sujeito de direitos e de quais direitos é titular, embora se depare com a frágil regulamentação destes direitos, oportuniza condições para que os respectivos deveres sejam correlatos aos direitos legais, os quais deverão ser assegurados pela família, sociedade e Estado, e exigidos por órgãos de defesa como M inistério Público, Poder Judiciário, Defensoria Pública e Conselho Tutelar. 
Neste sentido pretendemos apresentar a síntese do resultado do estudo referente à compreensão das possibilidades e limites enfrentados pelo Conselho Tutelar na articulação com a rede de proteção social, no município pesquisado, para nos aproximar da realidade dinâmica deste inovador órgão de defesa proposto pelo Estatuto da Criança e do Adolescente.

Para tanto, o levantamento preconizou sobre as estratégias adotadas pelo Conselho Tutelar para articular à rede socioassistencial, constatando que a utilização de ofício é um dos recursos adotados praticamente por todos os conselheiros tutelares na articulação da rede.

Outro aspecto selecionado pelos conselheiros tutelares participantes do estudo refere-se às reuniões mensais da rede socioassistencial como um dos instrumentos essenciais para tal articulação, discutindo-se as situaç̧ões de maior gravidade (crianças e adolescentes institucionalizados ou com risco de acolhimento institucional), nas quais se traçam estratégias para 0 atendimento da demanda por diversos órgãos do SGDCA.

Pode-se afirmar que a alteração estrutural proposta pelo ECA, com a implantação do Conselho Tutelar, proporcionou uma ruptura com o antigo sistema de atendimento proposto pelo Código de Menores, por intermédio da implementação de um órgão não jurisdicional com atribuição de efetivar providências administrativas para proteção dos direitos da criança e do adolescente.

Este novo paradigma se efetiva por meio de linhas de ação e das diretrizes da política de atendimento (artigos 87 e 88 do Estatuto), as quais preconizam a municipalização, descentralização político-administrativa, controle social, captação de recursos e a intersetorialidade, tendo como obrigatoriedade utilizar mecanismos e estratégias para a articulação da rede socioassistencial quando identificar situações de ameaça ou violação de direitos.

Konzen (2000) detecta que nenhum órgão ou agente da municipalidade foi investido com tantos instrumentos para a proteção dos direitos ao público infanto-juvenil como o Conselho Tutelar, tendo como uma das principais atribuições, expressas no artigo 136 do ECA, requisitar serviços públicos nas áreas de saúde, educação, serviço social, previdência, trabalho e segurança, e tal descumprimento da medida configurasse como prática de infração administrativa. Complementando, Andrade (2000, p. 32) afirma ainda que: 
[...] também é de sua responsabilidade tomar providências concretas e imediatas para sanar a situação denunciada. Sendo assim, criar estratégias para articulação da rede socioassistencial torna-se um desafio para o Conselho Tutelar diante da função de tutelar e defender quando há ameaça ou violação destes direitos.

Outras duas estratégias sugeridas pelas conselheiras tutelares para articulação da rede socioassistencial e que se diferenciaram dos demais depoimentos são: viabilizar reunião com o gestor público para pontuar deficiências existentes na rede de proteção social que impossibilitam assegurar os direitos dos menores locais; e representar sobre a falta de um atendimento ou equipamento social ao Ministério Público, órgão instituído na Constituição Federal (BRASIL, 1988), como guardião do segmento infância e juventude.

A estratégia citada de articular uma reunião com o gestor municipal, certificando-o das carências observadas nos atendimentos efetivados por este órgão, cumpre o objetivo de auxiliá-lo na elaboração da proposta orçamentária para planos e programas de atendimentos aos segmentos infância e adolescência, conforme preconiza as atribuições elencadas pelo artigo 136, do ECA.

0 acompanhamento desenvolvido pelo Conselho Tutelar consiste em verificar se a criança, o adolescente e sua respectiva família tiveram seus direitos resguardados nos encaminhamentos feitos aos órgãos referentes as diferentes políticas sociais. 0 não atendimento das requisições feitas pelo Conselho Tutelar ou a inexistência de um serviço que atenderia a demanda daquela criança ou adolescente, implica ao órgão iniciar procedimento de apuração de infração administrativa. Constatado o descumprimento injustificado de suas requisições o Conselho Tutelar tem como dever apresentar à autoridade judiciária a situação específica.

0 que não se pode admitir é a omissão do Conselho Tutelar em apresentar qualquer violação de direitos ocasionada pela inoperância das políticas setoriais simplesmente para evitar conflitos.

Os mecanismos determinados pela alteração legislativa do ECA produziram reflexos no cotidiano profissional do Ministério Público como guardião dos princípios constitucionais e órgão responsável por providenciar medidas judiciais e extrajudiciais, após verificadas pelo Conselho Tutelar as deficiências nos atendimentos das políticas setoriais que violam os direitos de crianças e adolescentes.

Para Konzen $(2000$, p. 23) "[...] 0 instrumento de provocação do controle é a ação civil pública, cuja titularidade restou conferida expressamente ao Ministério Público (artigo 
201, inciso V, do Estatuto)." Tem sido um instrumento de grande valia diante do descumprimento dos princípios constitucionais pelas diferentes esferas: federal, estadual e municipal.

Dos conselheiros tutelares entrevistados, todos mencionaram a existência de um acompanhamento pelo órgão dos casos de maior gravidade, requerendo uma fiscalização para verificar se a rede socioassistencial não está violando o direito da criança ou do adolescente que foram encaminhados por este órgão.

Observa-se que se faz presente nos trechos dos discursos dos conselheiros tutelares que o acompanhamento das demandas atrela-se à exigibilidade de direitos, ou seja, constatar se foram cumpridos diante dos encaminhamentos e requisições solicitadas.

Considera-se que o grande desafio é evitar que este direito se restrinja à exigibilidade individual - o que ficou claro nos relatos, e torná-lo uma exigibilidade coletiva. Por exemplo, houve recorrentes diálogos ao longo da coleta de dados deste estudo sobre a escassez de serviços na política pública da saúde, que ao assegurar um direito individual não traz garantia de que o coletivo em mesmas condições, seja igualmente atendido.

Dessa maneira, o resultado desta pesquisa corrobora com a afirmativa de Andrade $(2000$, p. 80$)$ ao apontar que "[...] tal conclusão não se deve ao fato de às crianças e adolescentes que demandaram ao Conselho a garantia do direito não terem sido atendidas, mas ao fato de que o Conselho não soube explorar todas as ferramentas de que dispunha [...]", pois cabe a esse órgão coletivizar as demandas individuais, transformando-as em demandas coletivas; articular ações junto à administração pública e também ao Conselho Municipal de Direitos da Criança e do Adolescente, provocando planejamento de ações que atendam à coletividade.

Em relação aos desafios encontrados pelos conselheiros para assegurar os direitos da criança e do adolescente, inevitavelmente aponta-se a falta de estruturação da rede de proteção social que atravanca o trabalho exercido pelo Conselho Tutelar conforme pontuado na pesquisa com incidência em quatro dos relatos.

Para a efetivação dos princípios propostos pelo Estatuto da Criança e do Adolescente, a legitimação do trabalho em rede foi identificado como um dos desafios encontrados pelos participantes, pontuando que a condição fundamental para tal finalidade relaciona-se a presença sólida do Estado em promover políticas públicas efetivas; 0 investimento na contratação de profissionais para atuar nos serviços socioassistenciais; e 0 
incentivo a participação da sociedade civil na gestão democrática, ocupando espaços de controle social como os conselhos de direitos.

0 acesso à rede para efetivação das políticas públicas para criança e adolescente trata-se de um artifício inovador ao implicar adoção de estratégias conjuntas e espaços de reflexão para atuação em casos de violação de direitos, prevista pela política de atendimento proposta pelo ECA em seus artigos 87 e 88 , que se darão por um conjunto de ações governamentais e não governamentais.

Um dos participantes ponderou como desafio a importância dos profissionais em relacionar a compreensão do contexto em que está submetida a família que violou o direito da criança e do adolescente, elemento de destaque diante das opressoras condições ofertadas pela exploração desenfreada do capitalismo.

É fácil a gente julgar. Ela é usuária de droga, ela não tem direito de ficar com 0 filho. Espera lá. 0 que levou ela a essa vida? 0 que foi proposto para ela? Qual a base que ela teve lá atrás? Ela teve amor, teve carinho, teve estudo? Tudo tem que se ponderar. Tem que dialogar. Não só agir. Oh, fez isso. Você não tem direito mais, vai perder seus filhos. Não é por aí. É um desafio. (Rosa - Conselheira Tutelar).

Quando o conselheiro tutelar atende uma família necessita planejar um ambiente acolhedor, sem estigmas e que resguarde a privacidade, efetivando uma ação dialógica para compreender as demandas que lhe estão sendo apresentadas para além da imediaticidade dos fatos e fenômenos; buscando reconhecer os determinantes estruturais e conjunturais que se apresentam de forma singular naquele caso específico, mas que, certamente, estão relacionados ao processo de produção e reprodução social peculiar à sociabilidade capitalista.

0 conhecimento resultante dos procedimentos da razão vai além da apreensão da imediaticidade da vida cotidiana. Ele busca captar a processualidade contraditória de seus objetos e visa a refiguração, no nível do pensamento, do seu movimento. 0 fenômeno é (apenas e necessariamente) o ponto de partida do conhecimento. Neste nível, o conhecimento se organiza mediante categorias analíticas. Estas são sínteses mentais dos nossos esforços em compreender o movimento do real, sua lógica constitutiva e de nos comportarmos adequadamente frente a ele. (GUERRA, 2009, p. 8).

Afinal, as expressões da questão social instauram-se no cotidiano das famílias através da violência; da falta de trabalho e de renda; da escassez de alimentação; moradia precária; da falta de acesso à saúde e educação, entre outros fatores que, na maioria das vezes, desencadeiam situações de ameaças ou violações de direitos mas as raízes das 
mesmas estão relacionadas à gritante desigualdade social que assola o Brasil. Dowbor (2008, p. 306) ressalta "[...] a visão que queremos aqui esboçar é que a transformação da família pertence a um conjunto de mudanças mais amplas e que não se trata apenas de lamentar sua dissolução: trata-se de repensar o processo de rearticulação do nosso tecido social."

É fundamental que o conselheiro tutelar se abstenha de qualquer tipo de estigma, preconceito ou imposição de valor moral nos atendimentos realizados com às famílias, uma vez que ao se reportar o processo histórico visualizam-se as diversidades existentes na organização familiar referentes à composição e a diferentes formas de sociabilidade que vigoram em seu interior, sempre influenciadas pelas determinações econômicas, políticas, sociais e culturais do tempo histórico.

Dessa maneira, não cabe aos atores do Sistema de Garantia dos Direitos à Criança e ao Adolescente reforçar a perspectiva do senso comum perpetuando um processo de culpabilização do indivíduo e/ou da família de forma totalmente desconectada das condições objetivas de vida, que são determinadas pela conjuntura sócio-histórica do país e daquela determinada localidade. Em tempos de capital financeiro mundializado, até mesmo uma pequena localidade - em um município de pequeno e médio porte, repercutem 0 projeto societário dominante e o ranço do neoconservadorismo.

Os dados coletados indicam que os limites e possibilidades entrelaçam no trabalho desenvolvido pelos conselheiros tutelares da localidade em estudo. 0 Conselho Tutelar, caracterizado como um órgão protagonista na defesa e exigibilidade de direitos à criança e ao adolescente e investido de instrumentos protetivos, depara-se com limites relacionados à falta de investimento do Poder Público na implantação de políticas públicas em todos os níveis.

Essa violação de direitos sociais pelo próprio Estado fica evidenciada na inoperância das políticas públicas traduzidas na falta de investimento na contratação de operadores para execução das políticas setoriais; no montante de recursos financeiros investidos para prestação dos diferentes serviços sociais; e, no débil estímulo à participação efetiva dos próprios usuários nas instâncias de poder decisório como os Conselhos Municipais de Direitos da Criança e do Adolescente.

É importante registrar a necessidade de capacitação continuada dos conselheiros tutelares - conforme estipulado pelo próprio ECA, sendo condição essencial para qualificar a efetivação das atribuições desse órgão considerando principalmente que, por ser inovador, é 
comum pairar dúvidas, equívocos diante de situações complexas que vivenciam nesse universo e que, muitas vezes, o conselheiro tutelar não se encontra preparado para enfrentar.

Em alguns depoimentos sobressaiu que nos atendimentos às famílias é importante ir além da imediaticidade dos fatos e reconhecer os determinantes estruturais e conjunturais que estão expostos cotidianamente, o que influência certamente nas situações de ameaças ou violações de direitos da criança e do adolescente por parte da família.

Considera-se a existência significativa de possibilidades para a articulação da rede socioassistencial, haja vista que o Conselho Tutelar exerce atividade de fiscalização das organizações governamentais e não governamentais e pode representar junto ao Ministério Público o descumprimento de suas medidas, motivo pelo qual é necessário 0 acompanhamento dos casos pelos conselheiros tutelares para verificar se os direitos foram realmente assegurados pela rede socioassistencial.

Do ponto de vista das autoras, observa-se que estas possibilidades são fragilmente exploradas pelos conselheiros tutelares, em nível nacional (índices expressivos de desigualdades sociais e desmantelamento dos direitos sociais); e também se deve ter cautela para evitar que esse órgão assuma à condição de apenas gerenciar e encaminhar as demandas para a rede de proteção social, do que assumir sua condição de protagonista para exigibilidade dos direitos.

Infere-se que ao contemplar as deficiências de funcionamento estrutural e as diferentes linhas de atuação dos Conselhos Tutelares, é de extrema importância e urgência histórica propiciar, além da infraestrutura adequada à organização desse órgão público, ações de capacitação inicial e permanente; politização para o fortalecimento deste órgão diante de um momento histórico de restrição dos direitos sociais; verificando-se que a promulgação da Lei no 12.696 (BRASIL, 2012) e da Resolução do Conanda № 170 ocorreu para minimizar e corrigir estas deficiências.

A discussão proposta permite compreender que apesar das mobilizações históricas da classe trabalhadora na esfera dos direitos no momento contemporâneo presenciam perdas, retrocessos e restrições atrelados a atender os interesses do capital que visa a óptica do mercado, adotando ações de incentivo ao voluntariado, à cultura da privatização e da desregulamentação do papel do Estado. 
Destarte, a perspectiva da proteção social e os interesses da reprodução da sociabilidade capitalista se diferem, impactando na vida das famílias com a produção de formas de desigualdades e exclusão e certamente no trabalho desenvolvido pelo Conselho Tutelar e pela rede socioassistencial.

É primordial enfatizar que os resultados obtidos nesta pesquisa contribuirão para a apreensão dos limites e possibilidades desta nova operacionalização proposta pelo Estatuto da Criança e do Adolescente (BRASIL, 1990) (em suas reformulações) e recomendada pelo Parecer CIJ no 04/2010 (SÃO PAULO, 2010), da Coordenadoria da Infância e Juventude do TJSP, na busca pela efetivação dos direitos das crianças e adolescentes, com intuito de qualificar a atuação dos atores envolvidos nesse contexto.

\section{Considerações finais}

Este ensaio demonstra que os reflexos da Lei № 12.010 (BRASIL, 2009) é uma temática instigante dada a proposta de aperfeiçoamento da sistemática prevista para a garantia dos direitos de crianças e de adolescentes à convivência familiar e comunitária, nos movendo para a apreensão do impacto que proporcionou o Parecer ClJ no 04/2010, emitido pela Coordenadoria da Infância e Juventude do TJSP. Para tanto, aproximamos de um recorte da realidade social do Estado de São Paulo, ou seja, um município de médio porte, para analisar os impactos do referido Parecer que determina o não ajuizamento de pedidos de providência e reforça as prerrogativas específicas do Conselho Tutelar e da rede socioassistencial na sistematização da atuação em prol da efetivação dos direitos da criança e do adolescente.

A interpretação do contexto histórico sobre a construção da política pública de atenção à infância e à adolescência revela processos de práticas repressivas, segregativas e de criminalização da pobreza existentes no país desde o período colonial, deparando-se com avanços no período em que o Brasil se reencontrou com a democracia.

Este reencontro teve início na década de 1980 e que, com duras lutas da sociedade civil organizada, culminou na promulgação da Constituição Federal (BRASIL, 1988) e assegurou visibilidade ao segmento criança e adolescente ao delimitar a condição de sujeitos de direitos e com prioridade absoluta.

O Estatuto da Criança e do Adolescente comparece no ordenamento jurídico brasileiro enquanto forma de regulamentação do artigo 227 da Constituição Federal (BRASIL, 
1988), absorvendo os princípios da proteção integral ao referido segmento populacional. A aprovação do Estatuto da Criança e do Adolescente, que também sofreu influência de normativas internacionais como a Declaração Universal dos Direitos da Criança, elegeu avanços no âmbito da proteção integral, da condição de sujeitos em desenvolvimento, dos deveres da família, da sociedade e do Estado e da necessidade da criação de políticas públicas para preservação destes direitos.

Os mecanismos determinados pela alteração legislativa do ECA (Lei ํ‥ 12.010 (BRASIL, 2009)) ratificou a responsabilização do Poder Público no cumprimento dos princípios constitucionais em prol das crianças, adolescentes e suas respectivas famílias. Inferiu sobre a integração entre o Conselho Tutelar, o M inistério Público e a Vara da Infância e Juventude, relevantes protagonistas no processo de construção e fortalecimento de políticas públicas de atenção à infância e à adolescência.

Porém, é imprescindível registrar que, apesar do empenho do Conselho Tutelar, da rede socioassistencial e do próprio Parecer $\mathrm{ClJ}$ no 04/2010, da Coordenadoria da Infância e Juventude do TJSP - que visa propor o fluxograma do atendimento à criança e ao adolescente, recolocando no devido "lugar" as atribuições de cada ente do Sistema de Garantia dos Direitos da Criança e do Adolescente - as questões estruturais determinadas pela "nova" configuração do Estado - perspectiva neoliberal - ocasiona impactos no desenho das políticas sociais que tem se orientado para a focalização, a seletividade enfim trilhando o caminho da desresponsabilização do Estado. Nesse contexto estão inseridos os direitos dos menores e suas respectivas famílias.

Em vista disso, o estudo sobre esta temática demonstrou que o ajuizamento dos fatos noticiados pelo Conselho Tutelar sobre ameaça ou violação de direitos anteriormente à adoção de medidas na esfera administrativa (conhecidos como "Pedidos de Providência"), reforça a judicialização e burocratização dos atendimentos, fragilizando o canal de acesso à cidadania e renovando velhos paradigmas conservadores de criminalização da pobreza. Portanto, considera-se benéfica a aplicabilidade deste parecer como mecanismo para determinação dos papéis no Sistema de Garantias de Direitos, inclusive do Poder Judiciário, Ministério Público, Conselho Tutelar e Rede Socioassistencial.

Sendo assim, acreditamos que o ajuizamento dos "pedidos de providência" estava na contramão dos princípios da proteção integral, prioridade absoluta, descentralização 
político-administrativa e municipalização, violando direitos constitucionais das famílias atendidas, exemplificadamente, a garantia do contraditório e a ampla defesa.

Por sua vez, a apreensão do conteúdo destes "processos de providência" retratava discussões dos profissionais sobre as expressões da questão social que não conduziam ao acesso de direitos por meio da implantação de políticas públicas, muito pelo contrário, restringia a assegurar demandas individualizadas. Nesta perspectiva, a pesquisa oportunizou compreender 0 novo fluxo de atendimento proposto pelas alterações à Lei ํo 12.010 (BRASIL, 2009).

Não pairam dúvidas sobre a relevância do Conselho Tutelar, um importante órgão criado pelo ECA para zelar pelos direitos da criança e do adolescente, revelando, no desenvolvimento deste estudo, que a atuação deste órgão é primordial para garantia destes direitos conforme preconizado pela Lei $n-12.010$ (BRASIL, 2009) e corroborado pela recomendação do Parecer ClJ № 04/2010, da Coordenadoria da Infância e Juventude do TJSP.

O que nos chama a atenção no cenário contemporâneo é que as legislações ofertam mecanismos relacionados aos deveres correlatos do cumprimento dos direitos da criança e do adolescente, mas ainda é pouco explorado, especialmente pelo Conselho Tutelar, evidenciando que a existência de dúvidas e 0 não cumprimento das atribuições por membros deste órgão implicarão em limitações para articulação desta rede.

0 desenvolvimento deste estudo nos permitiu concluir que, apesar dos indicativos estabelecidos pelo Parecer CIJ no 04/2010, da Coordenadoria da Infância e Juventude do TJSP, para corroborar com a sistemática de atendimento determinada pela Lei № 12.010 (BRASIL, 2009) preconizando a revisão de papéis para o funcionamento da rede socioassistencial, o que se constata nos relatos dos participantes é a dificuldade do cumprimento real da legislação pelas esferas estadual e municipal.

0 Estado não cumpre com a função de responder às demandas da sociedade com a distribuição de bens coletivos, produzindo conflitos de interesses com a imposição de desafios para o Conselho Tutelar e para a própria rede socioassistencial, no sentido de ultrapassar a visão tutelar (judicialização e criminalização da pobreza) para o ideário de garantia de direitos à criança, ao adolescente e sua respectiva família.

Embora o Estatuto da Criança e do Adolescente tenha sido criado na década de 1990, pode-se inferir a urgência histórica do investimento em pesquisa nacional para se 
identificar como se estrutura as violações de direitos e a dificuldade deste órgão público não jurisdicional - Conselho Tutelar - de efetivar a função a ele reportada.

Sendo assim, o desenvolvimento do estudo permitiu questionar se 0 Conselho Tutelar consegue erradicar práticas autoritárias, repressivas e criminalizadoras da pobreza? Consegue efetivar princípios que o define na lei como autônomo e não jurisdicional? Os membros do Conselho Tutelar são preparados para apreensão do significado de suas atribuições e o impacto social que o desenvolvimento de suas funções implicará na garantia dos direitos da criança e do adolescente? Será que a falta de estruturação da rede de proteção social, da precariedade de planejamento e do investimento em recursos humanos para instrumentalização destes serviços atravanca o trabalho exercido pelo Conselho Tutelar?

Sem dúvida, para a efetivação dos princípios propostos pelo Estatuto da Criança e do Adolescente, que consiste na legitimação do trabalho em rede - condição fundamental para tal finalidade - é primordial a presença sólida do Estado na promoção de políticas públicas efetivas; no investimento na contratação de profissionais para atuar nos serviços socioassistenciais; e no incentivo à participação da sociedade civil na gestão democrática, ocupando espaços de controle social como os Conselhos de Direitos da Criança e do Adolescente.

Postas todas estas considerações, o desenvolvimento desta pesquisa evidenciou um cenário contraditório quanto à afirmação dos direitos previstos pelo Estatuto da Criança e do Adolescente e suas respectivas alterações, justamente pela negação dos direitos sociais, que vêm sendo duramente ameaçados pelo ideário neoliberal que afasta o Estado de suas funções precípuas. 0 que nos leva a afirmar que nem sempre são esgotadas todas as possibilidades de atuação da rede socioassistencial com relação às demandas encaminhadas pelo Conselho Tutelar, levando à reprodução de práticas repressivas e criminalizadoras da pobreza previstas pelo antigo Código de M enores.

Desta forma, vale dizer que, com base nos depoimentos dos conselheiros tutelares participantes desta pesquisa, para fortalecer o exercício profissional neste espaço sócio ocupacional é requerido 0 acompanhamento dos casos encaminhados à rede de proteção social para constatar se os direitos foram resguardados, tendo em vista que, na maioria das vezes, não há uma devolutiva do acompanhamento da rede socioassistencial relacionada, na 
ocasião da pesquisa, em face da escassez de profissionais que integram os equipamentos sociais.

Sinaliza-se ainda que a pesquisa documental realizada nos registros do Conselho Tutelar do município estudado retratou os mais variados tipos de ameaça e violação de direitos, e o Conselho Tutelar desempenha o papel de agente de defesa para combater a omissão do Poder Público, demonstrando um forte potencial para provocar a implantação de políticas públicas.

Nesta perspectiva, entender a dimensão do trabalho desenvolvido pelo Conselho Tutelar perpassa por reconhecer, na perspectiva da totalidade, que a realidade social é travejada por contradições. Dessa forma, possibilidades e limites se entrecruzam na perspectiva de um órgão protagonista da defesa e exigibilidade de direitos à criança e ao adolescente, bem assim, investido de instrumentos protetivos necessários para buscar respostas a diversas situações de vulnerabilidade e riscos sociais que estão expostas as famílias, decorrentes de conjuntura imposta pela "nova" reconfiguração do sistema capitalista que não se altera na sua essência. Ou seja, a confrontação das classes sociais fundantes e a incessante reprodução de desigualdades sociais, através da acumulação capitalista, que é acirrada pela ampliação do processo de exploração da força de trabalho.

Em síntese, observa-se a existência significativa de possibilidades e estratégias ao constar que o Conselho Tutelar exerce atividade de fiscalização das organizações governamentais e não governamentais. Este órgão pode apresentar junto ao Ministério Público o descumprimento de suas medidas, por isso, o acompanhamento dos casos tornase uma tarefa primordial para verificar se os direitos foram realmente assegurados nos atendimentos propostos pela rede socioassistencial.

Neste sentido, a instrumentalização do Conselho Tutelar é um tema polêmico e exigirá esforços para a superação do desconhecimento da legislação que desencadeia o risco de atuar em funções que não lhe competem e acatar arbitrariedade principalmente do Ministério Público e Poder Judiciário, e para o fortalecimento do colegiado, ícone indispensável para o fortalecimento de sua autonomia. 0 fato é que, entre um embate e outro, a criança e o adolescente são sempre revitimizados, justamente por não se efetivar os seus direitos sociais.

Pelo exposto, conclui-se que os direitos sociais serão realmente concretizados a partir do comprometimento de uma diretriz política de governo e também pelo 
fortalecimento dos canais legitimados para a exigibilidade destes direitos. Razão pela qual o desenvolvimento de pesquisas sobre esta temática. Apesar de evidenciar apenas um recorte da realidade paulista, podemos inferir que exemplifica situações semelhantes que pairam sobre outros municípios, portanto, possui escopo contributivo ao estudo sobre os impactos da Lei no 12.010 (BRASIL, 2009), ao aperfeiçoar a sistemática prevista para a garantia dos direitos de crianças e adolescentes na convivência familiar e comunitária, tendo como base 0 Conselho Tutelar, órgão investido de instrumentos protetivos para zelar pelos direitos destes.

\section{Referências}

AGUINSKY, B. G.; ALENCASTRO, E. H. Judicialização da questão social: rebatimentos nos processos de trabalho dos assistentes sociais no poder judiciário. Katálysis, Florianópolis, v. 9, n. 1, p. 19-26, jan./jun. 2006.

ANDRADE, J. E. Conselhos tutelares: sem ou cem caminhos? São Paulo: Veras, 2000.

BRASIL. [Constituição (1988)]. Constituição da República Federativa do Brasil de 1988. Brasília. DF: Presidencia da Republica, 1988. Disponível em: http://www.planalto.gov.br/ccivil_03/Constituicao/Constituicao.htm. Acesso em: 3 abr. 2016.

BRASIL. Lei n. 12.010, de 03 de agosto de 2009. Dispõe sobre adoção; altera as Leis nos 8.069, de 13 de julho de 1990 - Estatuto da Criança e do Adolescente, 8.560, de 29 de dezembro de 1992; revoga dispositivos da Lei no 10.406, de 10 de janeiro de 2002 - Código Civil, e da Consolidação das Leis do Trabalho - CLT, aprovada pelo Decreto-Lei no 5.452, de 10 de maio de 1943; e dá outras providências. Diário Oficial da União, Brasília, DF, 4 ago. 2009. Disponível em: http://www.planalto.gov.br/ccivil_03/_ato20072010/2009/lei//12010.htm. Acesso em: 3 abr. 2016.

BRASIL. Lei n. 12.696, de 25 de julho de 2012. Altera o Estatuto da Criança e do Adolescente. Diário Oficial da União: Seção 1, Brasília, DF, p. 2, 26, jul. 2012. Disponível em: http://www.planalto.gov.br/ccivil/LEIS/L12696.htm. Acesso em: 30 jun. 2015.

BRASIL. Lei n. 8.069, de 13 de julho de 1990. Dispõe sobre o Estatuto da Criança e do Adolescente e dá outras providências. Diário Oficial da União, Brasília, DF, ano 127, n. 135, p. 13563, 13 jul.1990. Disponível em: http://www.planalto.gov.br/ccivil_03/leis//8069.htm. Acesso em: 17 abr. 2015.

CONANDA. Resolução n. 170, de 10 de dezembro de 2014. Altera a Resolução no 139, de 17 de março de 2010 para dispor sobre o processo de escolha em data unificada em todo 0 território nacional dos membros do Conselho Tutelar. Diário Oficial da União: Seção: 1, Brasília, DF, Ed. 18, p. 9, 11 dez. 2014. Disponível em: http://www.sdh.gov.br/sobre/participacao-social/conselho-nacional-dos-direitos-dacrianca-e-do-adolescente-conanda/resolucoes/resolucao-no-170. Acesso em: 10 jun. 2016. 
COSTA, A. P. M. Elementos que favorecem e incidiram sobre a criação do conselho tutelar. In: NAHRA, C. M. L.; BRAGAGLIA, M. (Org.). Conselho tutelar: gênese, dinâmicas e tendências. Canoas: Ed. ULBRA, 2002. p. 71-78.

DOWBOR, L. A economia da família. In: ACOSTA, A. R.; VITALE, M. A. F. (Org.). Família: redes laços e políticas públicas. 4. ed. São Paulo: Cortez, 2008. p. 293-316.

GUERRA, Y. A dimensão investigativa no exercício profissional. In: CFESS; ABEPSS. (org.). Serviço social: direitos sociais e competências profissionais. Brasília, DF, 2009. p. 701-718

KONZEN, A. A. Conselho tutelar, escola e família: parcerias em defesa do direito a Educação. Porto Alegre, 2000. Disponível em: http://www.mprs.mp.br/infancia/doutrina/id194.htm. Acesso em: 4 maio 2016.

LOPES, M. A escolha do melhor caminho. São Paulo: Rio de Janeiro: Livre Expressão, 2014.

MARTINELLI, M. L.; M ORAES, J. A importância categoria mediação para o serviço so cial. In: SEM INÁRIO LTINOAM ERICANO DE ESCUELAS DE TRABAJO SOCIAL, 20., 2012, CórdobaArgentina. Anais [...]. Córdoba: FAUATS, 2012. Disponível em:

http://www.cressrn.org.br/files/arquivos/Y6009Vi7X1700E584R0e.pdf. Acesso em: 23 maio 2016.

MILANI, G. D.; VOLPATO, L. M. B. O Serviço Social no Fórum de Regente Feijó: aspectos identificadores e abordagem do Parecer 04/2010 da Coordenadoria da Infância e Juventude sobre o Pedido de Providências. In: ENCONTRO TOLEDO DE INICIAÇÃO CIENTíFICA - PROF. DR. SEBASTIÃO JORGE CHAM MÉ, 2011, Presidente Prudente. Anais [...]. Presidente Prudente: Faculdades Integradas Toledo, 2011. Disponível em:

http://intertemas.unitoledo.br/revista/index.php/ETIC/article/ viewFile/3718/3478. Acesso em: 15 jun. 2016.

ONU. Declaração Universal dos Direitos das Crianças. Nova Iorque, 1959. Disponível em: http:// www .direitoshumanos.usp.br/index.php/Crian\%C3\%A7a/declaracao-dos-direitos-dacrianca.html. Acesso em: 15 jun. 2016.

SÃO PAULO. Tribunal de Justiça. Coordenadoria da Infância e Juventude. Parecer ClJ n. 04 $\angle 10$, de 18 de agosto de 2010. Pedidos de providências (ou verificatórios) - alterações legislativas - diretrizes para adequação procedimental para observância do devido processo legal, especialmente o contraditório e a ampla defesa na Infância e Juventude. Diário da Justiça do Estado de São Paulo, São Paulo, 27 ago. 2010. Disponível em: http://www.tj.sp.gov.br/Handlers/FileFetch.ashx?id_arquivo=28685. Acesso em: 25 nov. 2015.

SIERRA, V. M . A judicialização da política no Brasil e a atuação do assistente social na justiça. Katálysis, Florianópolis, v. 14, n. 2, p. 256-264, jul./dez. 2011. 